\title{
Catalytic Conversion of Synthetic Sulfur-Pollutants in Petroleum Fractions Under Different Photocatalyst Loadings and Initial Concentration
}

\author{
Mohamad Alif Hakimi Hamdan ${ }^{1}$, Nur Hanis Hayati Hairom ${ }^{1,3^{*}}$, Aishah Abdul Jalil ${ }^{2}$,Mohd Khairul \\ Ahmad $^{3}$, Rais Hanizam Madon ${ }^{1}$, Hazlini Dzinun ${ }^{4}$, Sofiah Hamzah ${ }^{5}$, Aida Syamira Mohd Kamal ${ }^{1}$, \\ Nurfatehah Wahyuny Che Jusoh ${ }^{2}$ \\ ${ }^{1}$ Faculty of Engineering Technology, Universiti Tun Hussein Onn Malaysia, Hab Pendidikan Tinggi Pagoh, KM 1, \\ Jalan Panchor, 84600, Muar, Johor, Malaysia, nhanis@uthm.edu.my \\ ${ }^{2}$ Centre of Hydrogen Energy, Institute of Future Energy, Universiti Teknologi Malaysia, UTM Skudai, Johor \\ 81310, Malaysia, aishahaj@utm.my \\ ${ }^{3}$ Microelectronic and Nanotechnology - Shamsuddin Research Centre, Faculty of Electrical and Electronic \\ Engineering, Universiti Tun Hussein Onn Malaysia, Parit, Raja, Batu Pahat, 86400, \\ Malaysia,akhairul@uthm.edu.my \\ ${ }^{4}$ Centre for Diploma Studies, Universiti Tun Hussein Onn Malaysia, Hab Pendidikan Tinggi Pagoh, KM 1, Jalan \\ Panchor, 84600, Muar, Johor, Malaysia, hazlini@uthm.edu.my \\ ${ }^{5}$ Faculty of Ocean Engineering, Technology and Informatics, Universiti Malaysia Terengganu, 21030 Kuala \\ Nerus, Terengganu Malaysia,sofiahhamzah@gmail.com
}

\begin{abstract}
In the oil and gas industry which applied to petroleum sources, thiophene is one of the sulphur contaminants that may harm the environment. The contents of sulphur in petroleum product gives out concern regarding the negative and harmful effect of sulphur contaminants onto environment and living health. One of the promising methods to degrade thiophene is photocatalytic degradation process. The usage of $\mathrm{ZnO}$ nanoparticles in photocatalytic degradation process has been wider due to its broad band gap, greater excitation of energy binding, and high stability. Several studies have discovered the ability of $\mathrm{ZnO}$ with capping agent in photocatalytic activity. Photocatalytic activity of photo-catalyst was affected by particle size, shape and morphology that are depending on the preparation method. Hence, this study put on priori-ties on synthesizing $\mathrm{ZnO}$ nanoparticles using precipitation method with the addition of KCC-1 which act as capping agent and used in the degradation of synthetic thiophene solution. The characterization of $\mathrm{ZnO}-\mathrm{KCC}-1$ using FTIR has confirmed that the successfulness produc-tion of $\mathrm{ZnO}-\mathrm{KCC}-1$ via precipitation method. There are three different loading of ZnO-KCC-1 (0.05 g/L, $0.10 \mathrm{~g} / \mathrm{L}$ and $0.15 \mathrm{~g} / \mathrm{L})$ and thio-phene concentration (100 ppm, $300 \mathrm{ppm}$ and $600 \mathrm{ppm}$ ) had been carried out in photocatalytic degradation of thiophene. The $\mathrm{pH}$ value for all fixed condition remains constant at natural $\mathrm{pH}$ range which is $\mathrm{pH} 7$. The optimum condition of degrading synthetic thiophene under natural $\mathrm{pH}$ range by using $\mathrm{ZnO}-\mathrm{KCC}-1$ is at its loading of $0.05 \mathrm{~g} / \mathrm{L}$ with the initial concentration of synthetic thiophene of 300ppm. The kinetic
\end{abstract}

study of this research has been confirmed to be at the first-order of kinetic reaction.

Keywords: KCC-1, ZnO-KCC-1, nanoparticle, photocatalytic degradation, thiophene.

\section{INTRODUCTION}

Thiophene is a heterocyclic compounds (heterocycle) which contain five membered rings with one sulphur molecule $\left(\mathrm{C}_{4} \mathrm{H}_{4} \mathrm{~S}\right)$. Thiophene molecule along with its derivative is presence in petroleum [1]. Therefore, photodegradation of the sulphur-content which is thiophene is an essential alternative to reduce the environmental burdens of fuels. In the recent year, attention has been given to the usage of photocatalytic oxidation due to cleaner and environment friendly to remove sulphur-containing compounds [2]. Previously, Hitam et al.[3]stated that besides being able to be recycle, photocatalytic oxidation is also said to has high catalytic activity, and consume less energy during process. The current technology used which is hydrosulfurisation (HDS) requires a very uncomfortable conditions such as high temperature, high pressure, and high consumption of hydrogen and end up in a high operating cost and severe gasoline loss [2].

Previously, a study on adsorption of thiophene and its derivatives has been done by using silver impregnated nanocrystalline metal oxides which the end result shows that metallic silver nano-particles does not effective in thiophene adsorption due to detailed studies showed that the active site of silver impregnated aluminium oxide is the $\mathrm{Ag}+$ ion which is coordinated to carbonate [4]. In addition, the photocatalytic oxidation of thiophene under visible light was conducted by using Pt/Pbs nanoparticles photocatalysts. However, the study shows a limited survey such that if the loading of the catalyst above $1.2 \mathrm{~g} / \mathrm{L}$, the penetration of the light to the photocatalyst 
is blocked and thus decrease the efficiency of the photocatalytic activity [5].

The objectives of the study are (1) to methodically prepare and characterize $\mathrm{ZnO}-\mathrm{KCC}-1$ nanoparticles via precipitation method, (2) to investigate the catalytic conversion of the synthetic sulfur-pollutants in petroleum fractions (thiophene) under different photocatalyst loading and initial concentration of thiophene, and (3) to elucidate the kinetic study of photodegradation of thiophene in petroleum fractions. In the meanwhile, the scopes of this research are to synthesis $\mathrm{ZnO}-\mathrm{KCC}-1$ nanoparticlesvia precipitation method followed by characterization of $\mathrm{ZnO}-\mathrm{KCC}-1$ by using Fourier Transform Infrared Spectroscopy (FTIR) in order to identify the chemical bonding between $\mathrm{Zn}$ and $\mathrm{O}$ in the nanoparticles. Investigation of the catalytic conversion of synthetic sulphur-pollutant in petroleum fractions (thiophene) under different loading of ZnO-KCC- $1(0.05 \mathrm{~g} / \mathrm{L}, 0.1 \mathrm{~g} / \mathrm{L}$ and 0.15 $\mathrm{g} / \mathrm{L}$ ) and initial concentration (100 ppm, $300 \mathrm{ppm}$, and 600 $\mathrm{ppm}$ ). The kinetic study of photodegradation of thiophene in petroleum fractions had been elucidated using zero order, 1st order and 2nd order. This research is considered successfully constructed as it can improve the environmental performance by reducing the amount of sulfur-pollutant in the petroleum fraction by photocatalytic activity thus is in line with the national agenda towards cleaner environment.

\subsection{Modified fibrous silica (KCC-1)}

Modified fibrous silica (KCC-1) is known as a new type of mesoporous silica material which has been an attention in many applications due to has greater surface areas, fibrousmorphologic, wide pore diameter, and high thermal stability. For example, catalysis, hydrogen storage, and capture conversion of $\mathrm{CO}_{2}$ [6]. However, the study on the application of KCC-1 is still on going by researchers. KCC-1 is mainly used for its high effectiveness due to its microstructures and mesostructured. Moreover, the fibrous morphologic of KCC-1 is expected to be enhancing the accessibility of actives sites and continuously improving its performance on adsorption process [6]. In addition, it allows the active molecules to disperse on the bigger internal surface area thus improves the performance of the catalysts [7]. On 1992, the previous chemically modified heteroatoms and organic functional groups was successfully changed into naturally porous materials as Mobil Oil Corporation scientists (USA) was the first to synthesize Mobil Composition of Matters MCM by surfactant-mediated self-assembly method [8]. This method assisting of surfactant templating pathway which opens a new type of materials known as mesoporous materials. In addition, a material is defined as porous material if the internal voids are able to fill in with gases [8]. The high area surface is due to the fibres of the fibrous instead of the size of the pores [9]. Thus, making KCC-1 the best and suitable catalyst support where there is a need for significant accessibility to active sites [9].

\subsection{Zinc Oxide ( $\mathrm{ZnO})$}

Zinc oxide used in nanoparticles structure mainly because they are highly reactive due to their small size and their high surface to volume ratio[10] - [11]. A lot of previous study that have been done on the usage of zinc oxide nanoparticles to act as photocatalysts in the degradation of dyes and resulted in as a good photocatalytic activity [12]. In the previous study, it stated that zinc oxide is a non-toxic and biocompatible structure[13]. Not only that, it is also simple and inexpensive to be synthesize. In addition, an article wrote by Ameta \& Sharma, clearly stated that zinc oxide nanoparticles are an excellent photocatalytic oxidation material as it can absorbs light in a larger spectrum[14]. Furthermore, $\mathrm{ZnO}$ was claimed has the highest photocatalytic activity efficiencydue to its great excitation binding energy and less toxic[15].

\subsection{Thiophene}

Thiophene is the simplest aromatic compound that contained in sulphur with the molecular formula of $\mathrm{C}_{4} \mathrm{H}_{4} \mathrm{~S}$ and has resemblance to benzene in the term of its chemical and physical properties. Aromatic species as thiophene are the common impurities in fuels due it is least reactive [16]. Thiophene is usually applied for research under catalytic C-S bond scission and hydrodesulfurization (HDS) mechanism due to the simple structureof molecule.

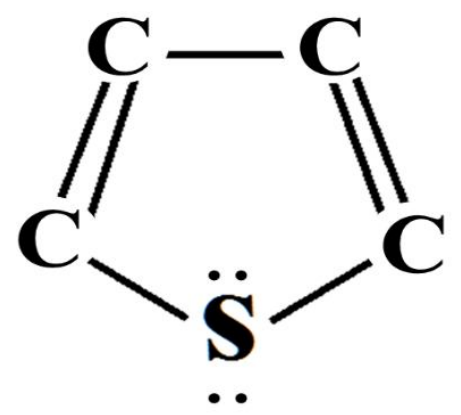

Figure 1: Schematic molecular structure [16]

\subsection{Photocatalytic degradation of Thiophene}

Photocatalysts is defined as any solid matters that can boost the reactivity of reactions in the presence of light while it is not consumed in the overall reaction. There are several good characterizations of a photocatalysts which are photoactive, able to utilize near UV light, biologically and chemically inert, photostable which is not easily prone to corrosive, cheap and lastly non-toxic [17]. There are several benefits when using photocatalytic degradation which are complete process of mineralization, there is no waste disposal problem, low in price and the temperature and the pressure are required in mild condition [17]. Photocatalytic reaction consists of the irradiation of a photon with the energy equal or higher than the band gap energy $(E g)$ of the catalyst, followed by the excitation of electrons from the valence band (VB) to the largely vacant conduction band (CB). Simultaneously, a hole $(\mathrm{h}+)$ with strong oxidizing ability is formed. Excited electrons 
(e-) are able to carry out reduction reactions and $h+$ can perform oxidation reactions [3].

Sulphur containing organic matters is defined as pollutant in the fuel and based on an article written by Lin et al., [2], the removal process of sulphur pollutants is difficult. Previously, due to its aromaticity and having low density, the inertness in thiophene causing it to be the most difficult sulphur pollutant to be oxidized using the conventional method which is oxidative desulphurization process. Therefore, an efficient photocatalyst method has been developed for the removal of sulphur content compound in fuel by photocatalytic oxidation. The efficiency of the photocatalytic degradation process does depend on the stability, particle size, surface area, band gap, and electron-hole recombination lifetime of the photocatalyst. Previously, many researchers have trying to improve and upgrade the photocatalyst by changing the preparation method of the photocatalysts, doping it with metals, and also by oxide mixing [5].

Photocatalytic degradation is an excellent and established advanced oxidation process used in the wastewater treatment. The advantages of using this method is that such as homogenous photo-Fenton is mineralized completely besides the process produces no sludge. In addition, it has faster rate of reaction at low cost and also operates well at ambient pressure and temperature condition. The process continuously receive attention because it has the potential of destroying a bigger range of organic chemical substrates [19].

\subsection{Proposed mechanism of photocatalytic degradation}

The proposed mechanism illustration of photocatalytic degradation is illustrated in order to be able to understand the mechanism of the process as shown in Figure 2. The performance of $\mathrm{ZnO}$ as a photocatalystis strongly associated with the electronic structure of it. Photogenerated holes $\left(\mathrm{h}^{+}\right)$in the valence band (VB) and electrons ( $\left.\mathrm{e}^{-}\right)$in the conduction band (CB) of the photocatalystis the first step to initiate photocatalytic degradation of an organic molecule/ion in solution. The generation of $\mathrm{h}^{+}$has a high oxidative potential, for direct oxidation of the organic molecule/ion to reactive intermediates. In addition, the reaction between $\mathrm{h}^{+}$with water and $\mathrm{OH}^{-}$anions and also the reaction between dissolved $\mathrm{O}_{2}$ and ecould generatereactive species which are hydroxyl radicals where highly assist in degradation of organic substrate due its reactive behaviour.

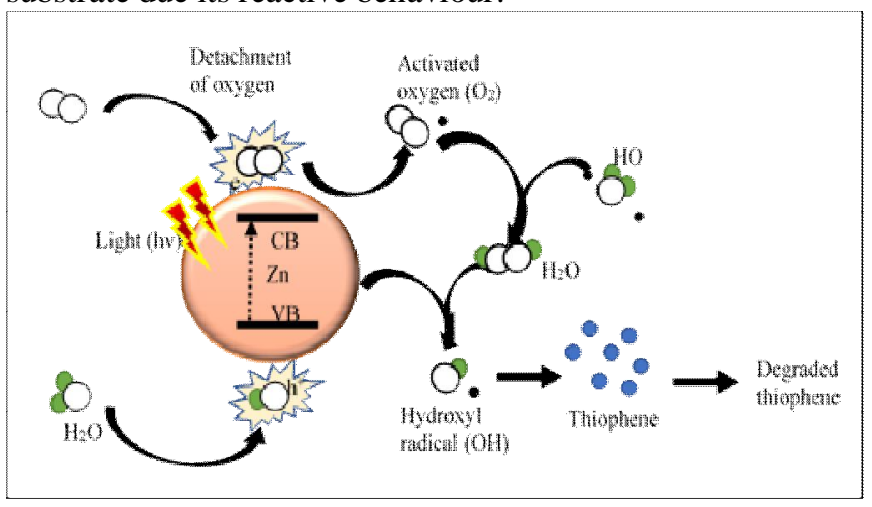

Figure 2:Proposed mechanism illustration for photocatalytic degradation of thiophene

\subsection{Kinetic study}

Kinetic study is the rates of chemical reactions which allows chemists to put on prediction the rate of reaction changes under certain conditions. Kinetic study is a priority due to it can elucidate the reaction mechanism information to the researcher. to elaborate kinetic study of degradation of thiophene, the Langmuir Hinshelwood (L-H) is used in order to describe the rate of photocatalytic degradation of thiophene [20]. In order to determine the rate of reaction of photocatalytic degradation of thiophene, the graph of $\ln \left(\mathrm{C} / \mathrm{C}_{\mathrm{o}}\right)$ versus time, $t$ at different loading of photocatalyst [19], [20].

The zero-order kinetic reaction commonly used as it is very simple along with good agreement for certain content in the photocatalytic process. The equation of zero order reaction is as follows:

$$
A_{t}=-k_{t}+[A]_{o}(1)
$$

The first order of reaction is conveyed by an expression of:

$$
\ln [A]_{t}=-k_{t}+\ln [A]_{o}(2)
$$

In addition, the $2^{\text {nd }}$ order of kinetic reaction is regard as follows;

$$
\frac{1}{[A]_{t}}=k_{t}+\frac{1}{[A]_{o}}(3)
$$

Where, $\mathrm{k}\left(\mathrm{min}^{-1}\right)$ is the apparent rate constant of the first-order rate, $A_{0}$ and $A_{t}$ are the concentrations of thiophene at reaction time 0 and $t$ respectively. $k_{a p p}$ is the kinetic behaviour of first order reaction which affected by initial organic content. It is used in the photocatalytic degradation to define the relationship between apparent first order of rate constant with the initial content of organic substrate. In addition, the rate of reaction depends on the intensity of light and catalyst absorption performance. Previous study stated by Y. Li et al.,[21] which the intensity of light affects the constant in the L-H model.

\section{MATERIALS AND METHODS}

\subsection{Synthesis of ZnO-KCC-1 Nanoparticles}

The synthesis of $\mathrm{ZnO}-\mathrm{KCC}-1$ nanoparticles was completed in the laboratory. $0.15 \mathrm{M}$ of oxalic acid were added into $500 \mathrm{ml}$ of distilled water in a $500 \mathrm{ml}$ beaker. While in another beaker, $0.1 \mathrm{M}$ of zinc acetate were added into $500 \mathrm{ml}$ distilled water. Both solutions in beakers were stirred slowly until reaches equilibrium condition for 5 minutes. After that, both solutions were mixed in $1 \mathrm{~L}$ beaker and then, $2 \mathrm{~g}$ of $\mathrm{KCC}-1$ were added into each beaker and heated at $60^{\circ} \mathrm{C}$ and stirred for 37 minutes using a hot plate stirrer. The precipitate that obtained was filtered by using filter papers with diameter (D110) in a manual filtration due to its nanoparticles size. The precipitate was then dried in an oven at $100^{\circ} \mathrm{C}$ for 60 minutes. 
Subsequently, the precipitate was then put into a furnace at $550^{\circ} \mathrm{C}$ for 180 minutes. Next, the dried precipitate was grinded manually by using a mortar to get the smoothest texture of the precipitate.

\subsection{Characterization of ZnO-KCC-1 Nanoparticles}

The characterization of $\mathrm{ZnO}-\mathrm{KCC}-1$ nanoparticles was done by using Fourier Transform Infrared Spectroscopy (FTIR) in order to observe the functional group of $\mathrm{ZnO}$ in the compound. Besides, the equipment also may define the chemical bond that exists in the particles.

\subsection{Photocatalytic degradation of Thiophene}

In this experiment, $2 \mathrm{~L}$ of photocatalysis reactor was used in a batch mode. The reactor was provided with a water-cooling system along with a condenser fitted on the top. The reactor has readily open up to UV lamp as an activation energy of photocatalyst. The photocatalyst, $\mathrm{ZnO}-\mathrm{KCC}-1$ were added into the reactor and the mixture was mixed using a magnetic stirrer at $300 \mathrm{rpm}$ for 30 minutes until the mixture reached the equilibrium adsorbate-adsorbent condition. Two main chemical substance, sodium hydroxide $(\mathrm{NaOH})$ and sodium chloride $(\mathrm{NaCl})$ was used in the process. The function of both main chemical substances is to adjust the $\mathrm{pH}$ solution that was measured using $\mathrm{pH}$ meter (EUTECH INSTRUMENTS, $\mathrm{pH}$ 700). The photocatalyst was added into the untreated synthetic thiophene solution at the condition of $0.2857 \mathrm{ml}$ of synthetic thiophene in $1000 \mathrm{ml}$ of acetonitrile before the photocatalysis process started. The loading of the photocatalyst were different on every initial at $0.05 \mathrm{~g} / \mathrm{L}, 0.1 \mathrm{~g} / \mathrm{L}, 0.15 \mathrm{~g} / \mathrm{L}$ and the photocatalytic degradation of thiophene were analysed at 3 parameter which are concentration, $\mathrm{pH}$ and turbidity. In addition, the initial concentration of the synthetic thiophene solution were differentiate at three reading which are 100 ppm, $300 \mathrm{ppm}$ and $600 \mathrm{ppm}$. Next, $50 \mathrm{ml}$ of treated synthetic thiophene solution were sampled at the interval time of 5 minutes. Next, the sampled solution was put into Eppendorf, 5804 model centrifuges in order to separate the precipitate of $\mathrm{ZnO}-\mathrm{KCC}-1$ from the treated solution. The centrifugal process was conducted at $5000 \mathrm{rpm}, 3^{\circ} \mathrm{C}$ for 20 minutes. Then, the treated synthetic thiophene solution was analysed by the UV-Vis spectrophotometric method. In the photodegradation process, percentage of degradation of thiophene was calculated using the following equation;

$$
\text { Photodegradation }=\frac{C_{o}-C_{t}}{C_{o}} \times 100(4)
$$

\subsection{Quality Analysis of Synthetic Thiophene Solution}

There are three synthetic thiophene solution quality analysis that were measured which are $\mathrm{pH}$ of synthetic thiophene solution, concentration of thiophene left in the solution and the turbidity of the solution. After the thiophene is degraded, the value of $\mathrm{pH}$ was measured by using the $\mathrm{pH}$ meter (EUTECH INSTRUMENTS, pH 700). In the meanwhile, the concentration of thiophene left in the synthetic solution were measured using the UV-Vis Spectrophotometer (Spectro UV-2650, Labomed. Inc.). After that, the turbidity of the waste water was measured using the turbidity instrument measurement (EUTECH Instrument TN100, 1000NTU) where the higher the turbidity value, the higher the amount of thiophene left in the solution.

\subsection{Kinetic study of photocatalytic degradation}

The kinetic study that were studied was based on the 3 order of reaction which are zero order, $1^{\text {st }}$ order and $2^{\text {nd }}$ order of reaction. The zero-order kinetic reaction commonly used as it is very simple along with good agreement for certain content in the photocatalytic process. The equation of zero order reaction is as follows:

$$
A_{t}=-k_{t}+[A]_{o}(5)
$$

In the meanwhile, the $1^{\text {st }}$ order kinetic reaction is as follows;

$$
\ln [A]_{t}=-k_{t}+\ln [A]_{o}
$$

In addition, the $2^{\text {nd }}$ order of kinetic reaction is regard as follows;

$$
\frac{1}{[A]_{t}}=k_{t}+\frac{1}{[A]_{o}}(7)
$$

The Langmuir Hinshelwood (L-H) will be used in describing the kinetic study of photocatalytic degradation by plotting the graph of $\ln \left(\mathrm{C}_{\mathrm{o}} / \mathrm{C}\right)$ versus time, t. The relationship of $\ln \left(\mathrm{C}_{\mathrm{o}} / \mathrm{C}\right)$ versus time, $\mathrm{t}$ can be seen by using this formula:

$$
\ln \frac{C_{o}}{C}=k_{1} t
$$

\section{RESULTS AND DISCUSSIONS}

\subsection{Fourier Transform Infrared Radiation Analysis}

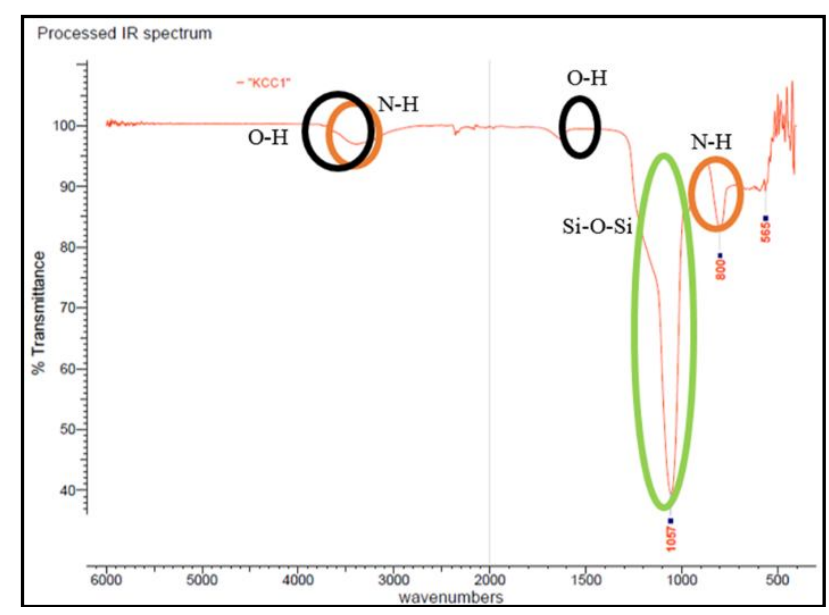

Figure3:FTIR pattern of KCC-1 


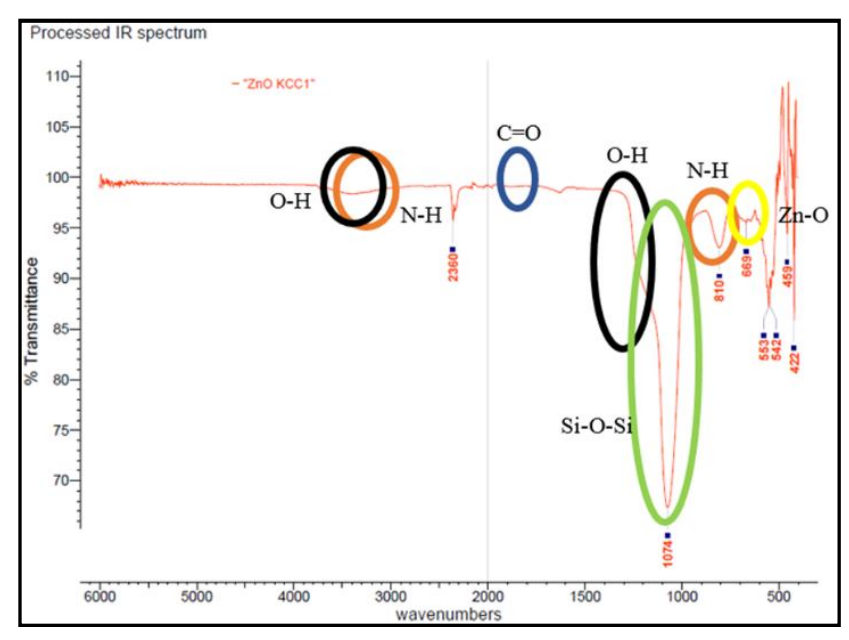

Figure4:FTIR pattern of $\mathrm{ZnO}-\mathrm{KCC}-1$

Hence, depending on the analysis made based on both Figure 3 and Figure 4 there are several common particles exist in both pattern which are $\mathrm{NH}$ bond, $\mathrm{Si}-\mathrm{O}-\mathrm{Si}$ bond, and $\mathrm{OH}$ bond. This hypothesis indicates that the combination of zinc oxide with KCC-1 had successful to generate the photocatalyst which is $\mathrm{ZnO}-\mathrm{KCC}-1$.

\subsection{Photocatalytic Degradation of Thiophene Under Different Photocatalyst Loading}

In this study, based on three different loading of photocatalyst which are $0.05 \mathrm{~g} / \mathrm{L}, 0.1 \mathrm{~g} / \mathrm{L}$ and $0.15 \mathrm{~g} / \mathrm{L}$ different initial turbidity value were achieved which are 5.20NTU, 5.00NTU and 12.51NTU respectively. This is due to increase in amount of photocatalyst loading that was inserted into the solution causing the presence of the foreign matter inside the solution does also increase.

Table 1:Turbidity value for different loading of $\mathrm{ZnO}-\mathrm{KCC}-1$

\begin{tabular}{|c|c|c|c|c|c|c|}
\hline \multirow[b]{2}{*}{$\begin{array}{l}\mathrm{Ti} \\
\mathrm{me}\end{array}$} & \multicolumn{2}{|c|}{$0.05 \mathrm{~g} / \mathrm{L}$} & \multicolumn{2}{|c|}{$0.10 \mathrm{~g} / \mathrm{L}$} & \multicolumn{2}{|c|}{$0.15 \mathrm{~g} / \mathrm{L}$} \\
\hline & $\begin{array}{l}\text { Turbi } \\
\text { dity } \\
\text { NTU }\end{array}$ & $\begin{array}{c}\text { Conver } \\
\text { sion } \\
(\%)\end{array}$ & $\begin{array}{l}\text { Turbi } \\
\text { dity } \\
\text { NTU }\end{array}$ & $\begin{array}{c}\text { Conver } \\
\text { sion } \\
(\%)\end{array}$ & $\begin{array}{l}\text { Turbi } \\
\text { dity } \\
\text { NTU }\end{array}$ & $\begin{array}{c}\text { Conver } \\
\text { sion } \\
(\%)\end{array}$ \\
\hline 15 & 0.89 & 33.33 & 0.75 & 27 & 0.45 & 83.3 \\
\hline 20 & 0.28 & 33.33 & 0.75 & 27 & 0.27 & 83.3 \\
\hline 30 & 0.28 & 33.33 & 0.15 & 81.82 & 0.27 & 83.3 \\
\hline 45 & 0.41 & 55.56 & 0.10 & 81.82 & 0.18 & 83.3 \\
\hline 60 & 0.17 & 88.89 & 0.22 & 81.82 & 0.42 & 83.3 \\
\hline
\end{tabular}

Based on Table 1, the condition under photocatalyst loading of $0.05 \mathrm{~g} / \mathrm{L}$ at time taken of 15 minutes with conversion of $33.33 \%$, the turbidity value is at 0.89 NTU. In the meanwhile, for both 20 minutes and 30 minutes of the experimental procedure, the percentage of conversion and turbidity value is constant at $33.33 \%$ and 0.28 NTU respectively. As for the variable time of 45 minutes, the turbidity value reaches $0.41 \mathrm{NTU}$ at conversion of $44.46 \%$. Then, at 60 minutes of running, the turbidity value changes into $0.17 \mathrm{NTU}$ at the best conversion of $88.89 \%$. Based on the collected data, the most efficient loading of photocatalyst is $0.05 \mathrm{~g} / \mathrm{L}$. Hence, by looking at Table 1 , the percentage of conversion is at their peak as it reaches conversion at $60 \mathrm{~min}$ degradation of thiophene. Meanwhile for loading of $\mathrm{ZnO}-\mathrm{KCC}-1$ at $0.15 \mathrm{~g} / \mathrm{L}$ the conversion value is constant from interval time of 15 minutes until it reaches 60 minutes at $83.30 \%$ with turbidity value different at each time $0.45 \mathrm{NTU}$, $0.27 \mathrm{NTU}, 0.27 \mathrm{NTU}, 0.18 \mathrm{NTU}$, and $0.42 \mathrm{NTU}$ respectively.

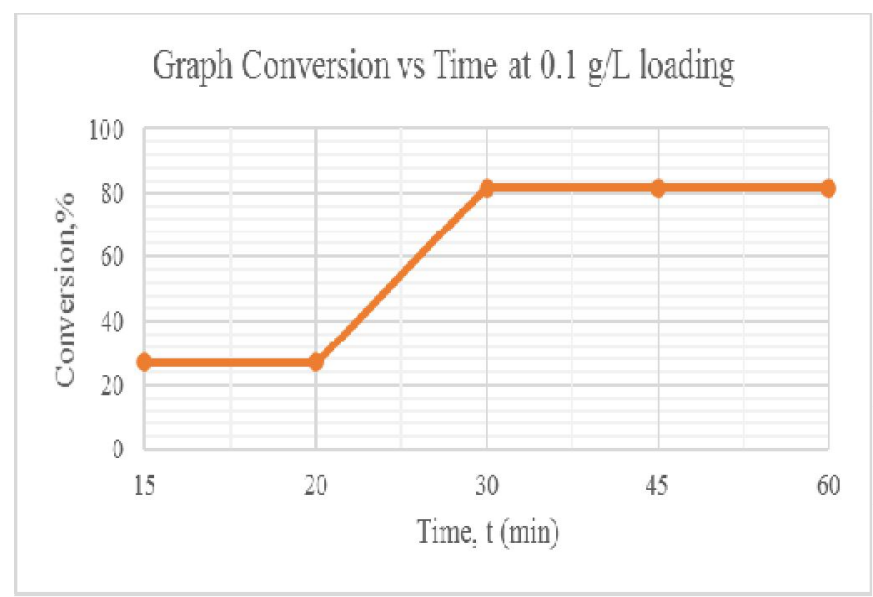

Figure5:Graph of conversion vs time at loading of $0.10 \mathrm{~g} / \mathrm{L}$

Based on Figure 5, the highest conversion peak at loading of photocatalysts of $0.10 \mathrm{~g} / \mathrm{L}$ is at $80 \%-90 \%$ at interval time of 30 minutes. However, the conversion was constant after 30 minutes. Theoretically, the higher the amount of the concentration of catalysts results to increasing number of active site available for adsorption. However, previous study made by Diya' Uddeen et al. stated that the increasing amount of catalyst concentration over certain fixed limit for the process does not gives any significant changes related to the efficiency of the degradation due to maximum limit of photon absorption within the reactor is reached[19].

\subsection{PhotocatalyticDegradation of Thiophene Under Different Initial Concentration}

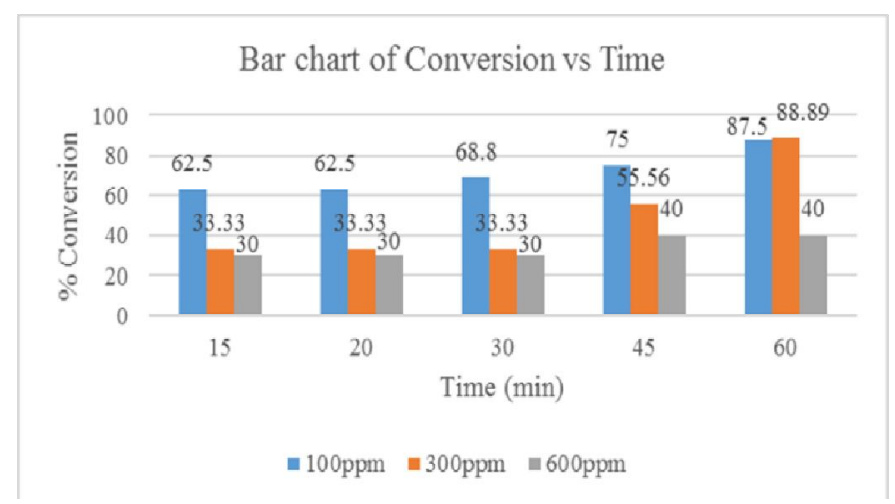

Figure6: Bar chart percentage of conversion against time in minutes. 
The most important factors that affects the photocatalytic activity efficiencyis concentration of thiophene. This is due to nature of characteristics of thiophene theoretically, the higher concentration of thiophene in the solution, results in higher foreign matter in the solution that need to be degraded. Furthermore,if the loading of the catalyst is lower, it will cause the production of organic molecule. This is mainly because of less transmitted radiation utilised in the reaction due to more light is transmitted through reactor [18].

The experimental procedure was conducted in purpose of studying the effect of three different concentration of thiophene at $100 \mathrm{ppm}, 300 \mathrm{ppm}$ and $600 \mathrm{ppm}$. Each of the concentration inserted using the same optimum loading of $\mathrm{ZnO}-\mathrm{KCC}-1$ at $0.05 \mathrm{~g} / \mathrm{L}$ under optimum $\mathrm{pH}$ at $\mathrm{pH}$ 7. Based on the bar graph showed in Figure 6, it clearly shows that at 15 minutes $100 \mathrm{ppm}$ concentration of thiophene were degraded at the loading of photocatalyst of $0.05 \mathrm{~g} / \mathrm{L}$ for conversion as much as $62.5 \%$. Meanwhile, for $300 \mathrm{ppm}$ the conversion percentage is $33.33 \%$ and the value was constant until it reaches time interval of 30 minutes. the same occurrence to the initial concentration of thiophene at $600 \mathrm{ppm}$ whereby the value of conversion was constant from variable time of 15 minutes until it reaches 30 minutes at conversion of $30 \%$. For the interval of 20 minutes, it shows that $100 \mathrm{ppm}$ concentration of thiophene were degraded at $62.5 \%$. Next, at 30 minutes, $100 \mathrm{ppm}$ concentration of thiophene were degraded at the conversion of $68.8 \%$. In the meanwhile, at the interval time of 45 minutes, all concentration ( 100 ppm, 300 ppm, $600 \mathrm{ppm}$ ) showed percentage of conversion where by the highest conversion is $100 \mathrm{ppm}$ at $75 \%$, followed by 300 ppm at $55.56 \%$ and $600 \mathrm{ppm}$ at only $40 \%$.

However, based on Figure 6 at variable time taken of 60 minutes, $100 \mathrm{ppm}$ and $300 \mathrm{ppm}$ showed degradation activity occurred at $87.50 \%$ and $88.89 \%$. Meanwhile constant degradation of $40 \%$ made on the concentration of thiophene at $600 \mathrm{ppm}$. Thus, it can be concluded that the optimum concentration of thiophene is $300 \mathrm{ppm}$. This is mainly because, looking at the percentage of degradation of thiophene at interval time of 60 minutes, $300 \mathrm{ppm}$ degraded as much as $1.39 \%$ higher $100 \mathrm{ppm}$ and $48.89 \%$ higher than initial concentration of thiophene of $600 \mathrm{ppm}$. Which likely to be favoured as at higher concentration of thiophene with lower loading of photocatalyst, higher degradation can be achieved.

\section{CONCLUSION}

As a brief declaration to the overall study of this research, this study was conducted with the aim to get the better of polluted characteristics presence of thiophene in the petroleum fractions which have backlash of organic material which will affect the environment if it is being release. Thus, the chosen method is photocatalytic degradation as a promising process in degrading the organic pollutant which is thiophene from the petroleum. Moreover, the photocatalyst used was $\mathrm{ZnO}-\mathrm{KCC}-1$ nanoparticles which is a novel photocatalyst in the scope of photocatalytic degradation of organic pollutant. The results obtained from the experimental conducted have successfully proved that the objectives of this study have been accomplished. The objectives are to methodically prepare and characterize $\mathrm{ZnO}-\mathrm{KCC}-1$ nanoparticles via precipitation method. Next, to investigate the catalytic conversion of sulphur-pollutants in petroleum fractions under different photocatalyst loading and initial concentration of thiophene. Besides, this research also aims to elucidate the kinetic study of photodegradation of thiophene in petroleum fractions. This study has successfully achieved the objectives as:

I. ZnO-KCC-1 nanoparticles were successfully synthesized via precipitation method. Characterization of ZnO-KCC-1 nanoparticles were successfully conducted by using Fourier Transform Infrared Spectroscopy (FTIR) The results show that the $\mathrm{ZnO}-\mathrm{KCC}-1$ contains $\mathrm{NH}$ and $\mathrm{OH}$ bond stretching and in deformation mode.

II. The optimum condition of photocatalytic activity of degrading synthetic thiophene in the presence of ZnO-KCC-1 nanoparticles which act as photocatalyst was successfully determined. The optimum condition is at initial concentration of synthetic thiophene at $300 \mathrm{ppm}$ in the presence of $0.05 \mathrm{~g} / \mathrm{L}$ ZnO-KCC-1 whereby the highest percentage of conversion was $88.89 \%$.

III. The kinetic study of photodegradation of synthetic thiophene in petroleum fractions were successfully determined by constructing graphs of $\ln \left(\left[\mathrm{C}_{0}\right] /[\mathrm{C}]\right)$ against time in minutes. The result shows that it follows the first-order kinetic reaction where the slope of the linear diagram $\left(\mathrm{R}^{2}\right)$ nearest to 1 at value 0.7707 . It can be concluded that photocatalytic degradation of synthetic thiophene can be successfully degraded in presence of $\mathrm{ZnO}-\mathrm{KCC}-1$ nanoparticles under the optimum condition.

\section{ACKNOWLEDGEMENT}

The authors gratefully acknowledge the financial and administrative support from Universiti Tun Hussein Onn Malaysia (UTHM) through GPPS Grant (H601) and Multidisciplinary Vot H473, Ministry of Higher Education Malaysia (MOHE) through Geran Kontrak Kementerian Vot K032and Collaborative Research Grant (CRG) 07G66 from Universiti Teknologi Malaysia.

\section{REFERENCES}

1. R. Mishra, K. K. Jha, S. Kumar, and I. Tomer, Synthesis, properties and biological activity of thiophene: A review, Der Pharma Chemica, vol. 3, no. 4, pp. 38-54, 2011.

2. Lin, F., Zhang, Y., Wang, L., Zhang, Y., Wang, D., Yang, Li, C.Highly efficient photocatalytic oxidation of sulfur-containing organic compounds and dyes on $\mathrm{TiO2}$ with dual cocatalysts $\mathrm{Pt}$ and RuO2, Applied Catalysis B: Environmental, vol. 127, pp. 363-370, 2012.

3. C. N. C. Hitam, A. A. Jalil, and S. Triwahyono, Synthesis of Zinc Oxide Supported on Titanium Dioxide for Photocatalytic Oxidative 
Desulfurization of Dibenzothiophene, Journal of Energy and Safety Technology (JEST), vol. 1, no. 1, 2018.

4. P. Jeevanandam, K. J. Klabunde, and S. H. Tetzler, Adsorption of thiophenes out of hydrocarbons using metal impregnated nanocrystalline aluminum oxide, Microporous and Mesoporous Materials, vol. 79, no. 1-3, pp. 101-110, 2005.

5. R. M. Mohamed and E. S. Aazam, New Visible $\square$ Light Pt/PbS Nanoparticle Photocatalysts for the Photocatalytic Oxidation of Thiophene, CLEAN-Soil, Air, Water, vol. 43, no. 3, pp. 421-426, 2015.

6. R. Hasan and H. D. Setiabudi, Removal of Pb (II) from aqueous solution using KCC-1: Optimization by response surface methodology (RSM), Journal of King Saud University-Science, vol. 31, no. 4, pp. 1182-1188, 2019.

7. N. Bayal, B. Singh, R. Singh, and V. Polshettiwar, Size and fiber density controlled synthesis of fibrous nanosilica spheres (KCC-1), Scientific reports, vol. 6, p. 24888, 2016.

8. Polshettiwar, V., Thivolle-Cazat, J., Taoufik, M., Stoffelbach, F., Norsic, S., \& Basset, J.-M. Hydro-metathesis of Olefins: A Catalytic Reaction Using a Bifunctional Single-Site Tantalum Hydride Catalyst Supported on Fibrous Silica (KCC-1) Nanospheres. Angewandte Chemie International Edition, vol. 50 no. 12, pp. 2747-2751, 2011.

9. M. Bouhrara et al., Nitridated fibrous silica (KCC-1) as a sustainable solid base nanocatalyst, ACS Sustainable Chemistry \& Engineering, vol. 1, no. 9, pp. 1192-1199, 2013.

10. S. Syama, P. J. Sreekanth, H. K. Varma, and P. V Mohanan, Zinc oxide nanoparticles induced oxidative stress in mouse bone marrow mesenchymal stem cells, Toxicology mechanisms and methods, vol. 24, no. 9, pp. 644-653, 2014.

11. N. Bayal, R. Singh, and V. Polshettiwar, Nanostructured Silica-Titania Hybrid using Dendritic Fibrous Nanosilica as a Photocatalyst, ChemSusChem, vol. 10, no. 10, pp. 2182-2191, 2017.

12. G. Nagaraju, G. C. Shivaraju, G. Banuprakash, and D. Rangappa, Photocatalytic activity of $\mathrm{ZnO}$ nanoparticles: synthesis via solution combustion method, Materials Today: Proceedings, vol. 4, no. 11, pp. 11700-11705, 2017.

13. Nguyen, L. T. T., Nguyen, L. T. H., Duong, A. T. T., Nguyen, B. D., Quang Hai, N., Chu, V. H., Bach, L. G.Preparation, characterization and photocatalytic activity of La-doped zinc oxide nanoparticles, Materials, vol. 12, no. 8, p. 1195, 2019.

14. P. Rathore, A. K. Chittora, R. Ameta, and S. Sharma, Enhancement of photocatalytic activity of zinc oxide by doping with nitrogen, Sci. Revs. Chem. Commun, vol. 5, pp. 113-124, 2015.

15. N. H. H. Hairom, A. W. Mohammad, and A. A. H. Kadhum, Effect of various zinc oxide nanoparticles in membrane photocatalytic reactor for Congo red dye treatment, Separation and Purification Technology, vol. 137, pp. 74-81, 2014.

16. N. Y. Dzade and N. H. De Leeuw, Adsorption and Desulfurization Mechanism of Thiophene on Layered FeS (001),(011), and (111) Surfaces: A Dispersion-Corrected Density Functional Theory Study, The Journal of Physical Chemistry C, vol. 122, no. 1, pp. 359-370, 2018.

17. D. S. Bhatkhande, V. G. Pangarkar, and A. A. C. M. Beenackers, Photocatalytic degradation for environmental applications-a review, Journal of Chemical Technology \& Biotechnology: International Research in Process, Environmental \& Clean Technology, vol. 77, no. 1, pp. 102-116, 2002.

18. A. Gnanaprakasam, V. M. Sivakumar, M. Thirumarimurugan, Influencing Parameters in the Photocatalytic Degradation of Organic Effluent via Nanometal Oxide Catalyst: A Review, Indian Journal of Materials Science, vol. 2015, no. 2, pp. 1-16, 2015.

19. B. H. Diya'uddeen, W. M. A. W. Daud, and A. R. A. Aziz, Treatment technologies for petroleum refinery effluents: A review, Process safety and environmental protection, vol. 89, no. 2, pp. 95-105, 2011.

20. Lee, K. M., Abd Hamid, S. B., \& Lai, C. W. Mechanism and Kinetics Study for Photocatalytic Oxidation Degradation: A Case Study for Phenoxyacetic Acid Organic Pollutant. Journal of Nanomaterials, vol. 2015, no. 1, pp. 1-10, 2015.

21. Y. Li, S. Sun, M. Ma, Y. Ouyang, and W. Yan, Kinetic study and model of the photocatalytic degradation of rhodamine $B$ (RhB) by a TiO2-coated activated carbon catalyst: Effects of initial $\mathrm{RhB}$ content, light intensity and $\mathrm{TiO2}$ content in the catalyst, Chemical Engineering Journal, vol. 142, no. 2, pp. 147-155, 2008. 